a certain extent the amorphous base, leaving a residue that approaches very near the composition of the second mineral, $B$. Now if the conditions are favourable, $B$ will exhaust the residue until that approaches in composition to $C$; and so on.

If, however, the conditions that were favourable to the formation of more $A$ were prevented from continuing, the residue would not perhaps be suitable to the formation of $B$, but to another mineral which we will call $X$. This $X$ may, in its turn, leave a residue from which would not form $C$ but another species $Y$. We should in this way have two rocks derived from the same magma and having the same chemical composition, yet differing widely in their mineral components, which using the above letters could be represented thus :

$$
\mathrm{A}+\mathrm{B}+\mathrm{C}=\mathrm{A}+\mathrm{X}+\mathrm{Y} \text {. }
$$

\title{
V.-On the Discovery of Human Bones and Ornaments in a Cave in the Great Ormes Head.
}

By the Rev. Canon A. H. Winvington Ivgram, F.G.S.

CAVE in the south escarpment of the Great Ormes Head has
been in gradual process of exploration by a person named Kendrick. In its silt and breccia he has discovered fragments of human skeletons, indicating by their dimensions that the individuals to whom they belonged were about five feet six inches in height. Some of their tibiæ are still to be seen imbedded in situ. There has also been found a considerable quantity of swine's teeth, each marked on the fang with from four to six transverse lines, and perforated at the extremity with a hole through which ran probably a tendon of a reindeer or some other ligament stringing them together as a necklace. There is a similar one, composed of human teeth, in the Christie Collection in the British Museum, worn by the inhabitants of the Solomon Islands. From the same cave deposit there have been extracted several bears' teeth, with a hole in each of them for their suspension as ear-rings, and two lower equine jaws with the enamel of the four incisors highly polished, and with zigzay marks on the surface of the maxillary bone. These were probably hung also from the necks of the cave-men as ornaments. ${ }^{1}$ The whole cavern, or a portion of it, has been considered to have formed a burial-place for some Iberian tribe; but the careless and irreverent manner in which the dead in it appear to have been disposed of seems to indicate that it might have been the habitation of a race of cave-men akin to the Eskimos, whom Professor Boyd Dawkins, in his "Early Man in Britain," describes as so indifferent to the sepulture of their deceased relatives that they sometimes cover up their bodies with snow and leave them to be eaten by dogs or foxes. The cave, which contains a natural reservoir of water, has only been partially excavated, and further researches seern most desirable, as they might lead to the finding of very important relics of its original inhabitants, as well as settle any doubts which may have arisen as to the accuracy of the present explorer's statement, on which the truth of the discovery of the above-mentioned remains in that particular cave rests.

\footnotetext{
1 In the same way as the natives of New Guinea wear lower human jaws as bracelets.
} 